\title{
EFEITO DE UM CORANTE INCORPORADO A TRÊS VIDRADOS DE LOUÇA EM GRÉS
}

\author{
Jordana Mariot Inocente ${ }^{\prime}$ \\ Ana Filipa Neves ${ }^{2}$ \\ Pedro Mantas ${ }^{2}$ \\ Alexandre Zaccaron ${ }^{3}$ \\ Vitor de Souza Nandi ' \\ Renato Dagostim Pasini ${ }^{4}$
}

\section{Resumo}

Com a evolução industrial e exigência do mercado, o processo de fabricação de cerâmica de revestimento teve a necessidade de produzir materiais com tonalidades mais próximas. A dificuldade em alcançar esse objetivo é muito difícil, devido às inúmeras variáveis no processo produtivo. Porém, com estudos técnicos nas áreas dos vidrados e corantes isto é possível. Neste trabalho foram comparados vidrados cerâmicos (mate, opaco e transparente) com quantidades variáveis em peso de corante verde ( $1 \%, 3 \%, 5 \%$ e $7 \%)$, e analisado o efeito que a adição deste corante apresenta em cada vidrado. Para este estudo foram utilizadas as técnicas de caracterização de DRX, dilatometria, colorimetria e rugosidade superficial. Os resultados obtidos através das análises de DRX mostraram que o zircão é o veículo transportador do cromóforo da cor verde. A dilatometria foi alterada com adição de $7 \%$ do corante baixando os coeficientes de dilatação em até 4 pontos. A análise colorimétrica indicou que a cor verde foi bem desenvolvida, e apresentou saturação com $7 \%$ de corante nos vidrados mate e opaco, e a rugosidade superficial não sofreu alteração com os percentuais de corante adicionado

Palavras-chave: Vidrados; Corantes; Louça grés; Tonalidade.

\section{EFFECT OF A DYE INCORPORATED THREE DISHES OF GLAZED STONEWARE}

\begin{abstract}
With the industrial revolution and market demand, the ceramic coating manufacturing process was a need to produce materials with closest shades, that is, without abrupt variations of color in the same product type. The difficulty in reaching this goal is very difficult because of the many variables in the production process. However, with the development of technical studies in the field of glazing and dyes this is possible. In this work we were compared ceramic glazes (matt, opaque and transparent) with varying amounts in weight green dye (1\%, 3\%, $5 \%$ and $7 \%)$, and analyzed the effect that the addition of this dye has on each glaze. For this study we used the techniques of characterization of XRD, dilatometry, colorimetry and surface roughness. The results obtained through XRD analysis showed that the zirconia is the carrier vehicle of the green chromophore. The dilatometry was changed with the addition of $7 \%$ of the dye lowering the coefficient of up to 4 points. The colorimetric analysis indicated that the green was well developed, and were saturated with $7 \%$ dye in matte and opaque glazed, and the surface roughness did not change with the percentage dye added.
\end{abstract}

Keywords: Glazed; Dyes; Stoneware dishes; Shades.

'Centro Universitário Barriga Verde - UNIBAVE, Cocal do Sul, SC, Brasil. E-mail: jordanainocente@hotmail.com

${ }^{2}$ Departamento de Engenharia de Materiais e Cerâmica, Universidade de Aveiro, Portugal.

${ }^{3}$ Universidade do Extremo Sul Catarinense - UNESC, Criciúma, SC, Brasil.

${ }^{4}$ Colégio Maximiliano Gaidzinski - CMG, Cocal do Sul, SC, Brasil. 


\section{INTRODUÇÃO}

Nos revestimentos e louças cerâmicas, o suporte cerâmico é recoberto por uma camada vítrea, genericamente denominada de vidrado, que tem como função revestir o corpo cerâmico com uma capa uniforme e impermeável, realçando a sua função estética ou decorativa, adaptando as suas necessidades de uso, como por exemplo: resistência ao desgaste, facilidade de limpeza, resistência à ação dos produtos químicos com os quais entrará em contato, entre outras [I].

Durante muito tempo, as peças cerâmicas vidradas foram obtidas apenas por processos artesanais ou artísticos, nas quais a reprodutibilidade de cores na decoração, entre diferentes peças ou numa mesma peça, nunca foi o principal objetivo [2]. Com o passar dos tempos a cerâmica passou por um grande processo de melhoramento e a industrialização veio trazer uma produção em série de produtos cerâmicos vidrados, surgindo a necessidade do conhecimento técnico de reações químicas e físicas, e conhecimentos na área industrial e laboratorial do comportamento dos vidrados e substratos cerâmicos, para conhecer a maneira correta de produzir as mesmas tonalidades em variáveis produtos. Obter a reprodutibilidade da tonalidade passou a ser uma exigência dos consumidores.

Para os consumidores finais, muitas vezes a estética do produto acabado assume papel mais preponderante do que as propriedades técnicas que indicam o desempenho do mesmo frente às solicitações exigidas [3].

Segundo Sichi, os desenvolvimentos no setor dos corantes cerâmicos beneficiaram muito a sua qualidade e a sua economia [4]. Pode-se definir o vidrado cerâmico como: fina camada de natureza vítrea, com ocasional presença de fases cristalinas não fundidas ou recristalizadas, preparadas a partir de misturas que, na fusão se unem a um suporte cerâmico, tornando-se insolúveis e impermeáveis aos gases e líquidos [I]. Esta camada deve-se adaptar a um substrato cerâmico para se obter uma forma, cor e características superficiais desejadas, ocorrendo para isso uma reação mais ou menos intensa entre ambos. No caso dos vidrados, sua consolidação ocorre por meio da sinterização de materiais com elevada superfície específica (maioritariamente materiais de natureza vítrea), depositados sobre a superfície cerâmica [2].

O substrato (base cerâmica) também sofreu uma evolução muito grande desde o começo do seu uso em escala industrial. Atualmente, é dividido por sua tipologia e características técnicas, como: monoporosa, porcelanato, grés, entre outros.

grés é um tipo de pasta cerâmica que queima a alta temperatura, como a porcelana, e tal como esta, possui também grande dureza. O termo grés tem origem francesa. O grés cerâmico compreende produtos tais como: ladrilhos, louça de mesa, louça sanitária, louça artística, etc [5].

A composição do grés não necessita utilizar matérias primas tão puras como as da porcelana, pois as peças podem apresentar alguma coloração. Em termos de custos, é mais vantajoso do que produzir produtos com matérias primas de alta pureza, que possuem um valor consideravelmente mais alto. Estas têm que queimar a temperaturas que variam entre $1150^{\circ} \mathrm{C}$ e $1300^{\circ} \mathrm{C}$. Após a queima as peças tornam-se impermeáveis, vitrificadas e opacas. Uma das características mais importantes destes produtos é a sua baixa absorção de água e alta resistência mecânica [6]. Os vidrados e os corantes cerâmicos são materiais que deveriam ser compatíveis entre si, mas na prática, geralmente, isso não acontece. Os vidrados têm certos requisitos de queima, dilatação térmica, entre outros.

Já os corantes têm exigências quanto às condições ideais de processamento para o desenvolvimento da coloração desejada, como por exemplo a sua granulometria entre outros. $O$ resultado é que existe entre estes dois componentes uma diferença, como uma incompatibilidade química, pois o corante só aparecerá durante a queima como consequência da sua lenta reação entre os componentes dos corantes e as composições dos vidrados [2]. De maneira geral, pode-se dizer que existem dois mecanismos gerais para colorir um vidrado:

(i) Desenvolvimento da cor na rede do silicato, como parte integrante da mesma, sendo íons solúveis que originam colorações e formam parte da rede vítrea ou suspensões coloidais distribuídas nos vidrados; e

(ii) Inclusões ou mistura na estrutura do vidrado de partículas individuais de pigmentos calcinados.

A cor observada se define subjetivamente como a sensação provocada pela luz visível (região onde somente ondas com comprimentos específicos compreendidos entre 400 a $700 \mathrm{~nm}$, estimulam a retina do olho) que se caracteriza por ser capaz de sensibilizar o olho humano [7]. O comprimento de onda que transmite a cor verde, por exemplo, situa-se entre 500 e 570 nm [2].

O tamanho de partículas é um fator muito importante no desenvolvimento da cor nos vidrados. Dimensões muito grandes de partícula do corante levam a diminuição do poder de reatividade e, por outro lado, dimensões muito pequenas tendem a diminuir a intensidade da cor ou induzem fenômenos de destonalização [2].

Quando se aplica um vidrado a um revestimento, espera-se que ocorra o mecanismo de coloração, com diferentes intensidades e desempenho, devido a diferentes percentagens de corante utilizado no material e também aos diferentes tipos de vidrados utilizados. Industrialmente os vidrados são divididos em grandes grupos de acordo com as suas características de trabalho: transparentes, mates e opacos. A opacidade é conseguida pela adição de compostos que não fundem completamente, formando pequenos cristais que causam difusão da luz, sendo mais ou menos intensa conforme o tamanho e o caráter dispersante das partículas adicionadas. Os óxidos mais utilizados para esse efeito são: óxido de estanho, de zircônio, de alumínio, de arsênio, etc. Um vidrado mate contém, em geral, partículas 
opacificantes de tamanho reduzido à superfície, as quais quebram a refração espectral. Os vidrados mates possuem também zircônio, devido não só à opacidade, mas também à brancura que este confere. Um vidrado transparente envolve uma parte vítrea e um material cristalino que retarda a maturação da frita, mas que acaba também por fundir completamente. É geralmente muito brilhante e transparente, onde se consegue ver o substrato do material no qual foi aplicado, mas podendo também ter coloração [8].

Deste modo, tem-se como objetivo analisar o efeito de um corante (verde) quando incorporado a três vidrados diferentes (opaco, mate e transparente), avalia-se a excepcionalidade de cada vidrado além dos diferentes níveis de desenvolvimentos da cor, bem como, qual percentual de corante é preciso para o esmalte saturar.

\section{METODOLOGIA}

Utilizaram-se três suspensões de vidrado com composições diferentes (mate, opaca e transparente) fornecidas gentilmente por uma empresa da região de Aveiro em Portugal. A densidade dos vidrados foi determinada através de um picnômetro (Servitech, $100 \mathrm{ml}$ ).

Posteriormente determinou-se a quantidade de sólidos, para esse feito, foram pesadas $100 \mathrm{~g}$ de cada tipo de vidrado em uma balança laboratorial da (marca JB Balanças, modelo AD200, com precisão de $0,00 \mathrm{lg}$ ), posteriormente colocadas numa estufa (marca Fanem 3 I 5 3E) para a eliminação total da água a $100 \pm 10^{\circ} \mathrm{C}$ por $24 \mathrm{~h}$. Desta forma, pôde-se calcular a quantidade de corante que foi incorporado à suspensão. O cálculo do percentual de sólidos foi realizado conforme Equação I.

$$
\% S=\frac{P_{i}-P_{f}}{P_{i}} \times 100
$$

Onde:

$\% \mathrm{~S}=$ Percentual de sólidos da amostra (\%)

$\mathrm{Pi}=$ Massa inicial $(\mathrm{g})$

$\mathrm{Pf}=$ Massa final após secagem da amostra $(\mathrm{g})$

As técnicas utilizadas para caracterizar os vidrados foram as seguintes: difração de raios $X$, análise dilatométrica análise colorimétrica e análise da rugosidade superficial. A técnica de caracterização difração de raios $X$ foi usada para identificar as fases cristalinas presentes no material. Com um aparelho da marca Rigaku, tipo Geigerflex, foi usado uma ampola de cobre com um comprimento de onda de I,54056 ̊. As fases presentes nas amostras foram posteriormente identificadas com o auxílio de um software DIFFRACplus - EVA, com a base de dados centrada no sistema JPCDS.

A análise dilatométrica determinou o comportamento das amostras (dilatação/retração) quando são aquecidas ou arrefecidas, refletindo em mudanças nas propriedades físicas, estruturais e químicas das amostras (mudanças de fases e de tamanho das partículas) [9]. Utilizou-se um dilatômetro BAHR Thermoanalyse $\mathrm{GmbH} 2000$, tipo DIL 80IL, no intervalo de temperaturas $100-1000^{\circ} \mathrm{C}$, com uma velocidade de aquecimento de $10^{\circ} \mathrm{C} / \mathrm{min}$. Foram realizadas as dilatações apenas das quantidades de $7 \%$ de corante, devido a sua maior proporção.

Para as análises colorimétricas e de rugosidade foram confeccionados 15 corpos de prova com quatro porcentagens diferentes do corante estudado, bem como, a amostra padrão de cada tipo de vidrado (Tabela I).

Com o percentual de sólido calculado de cada vidrado, pesou-se $300 \mathrm{~g}$ de cada tipo e adicionaram-se as quantidades de corante verde conforme Tabela I. Em seguida se manteve em agitação constante em um agitador laboratorial, por um tempo determinado de 5 min para a devida homogeneização do corante com os vidrados.

Para sua aplicação foram utilizadas placas cerâmicas de revestimento tipo grês porcelanato $(10 \mathrm{~cm} \times 10 \mathrm{~cm})$, onde inicialmente foi aplicada uma pequena quantidade de água com o auxílio de uma esponja, e posteriormente aplicado os vidrados com o auxílio de um binil (Servitech) com abertura de $0,4 \mathrm{~mm}$. As quais foram introduzidas em uma estufa (Fanem $3153 \mathrm{E})$ a $100 \pm 10^{\circ} \mathrm{C}$ por $20 \mathrm{~min}$, para posterior queima em um forno tipo mufla (Quimis modelo $\mathrm{Q} 3$ I8S) a uma temperatura de $1170^{\circ} \mathrm{C}$ a uma taxa de aquecimento de $10^{\circ} \mathrm{C}$ min, com patamar de queima de 2 horas. Com os corpos de prova já sinterizados iniciou-se as análises colorimétrica e de rugosidade superficial.

Para a análise colorimétrica utilizou-se de um colorímetro Minolta CR 300 . Após a calibração do equipamento, utilizando uma amostra de referência branco, de sulfato de bário, efetuou-se as leituras das coordenadas colorimétricas (L, a, b). Seu princípio de funcionamento consiste em medir e analisar a intensidade e composição da cor, transformando em números as principais características da cor. A análise pode ser assim feita de modo objetivo baseando-se nos parâmetros colorimétricos L*, a* e b*. Esses parâmetros representam os eixos de um diagrama tridimensional (Figura I). Valores positivos de $\mathrm{a}^{*}$ indicam cores vermelhas, enquanto que valores negativos representam cores verdes. Da mesma forma, valores positivos de $b$ * demonstram cores amarelas e valores negativos demonstram cores azuis. L*é uma medida da escala de cinza, entre o preto e o branco, em uma faixa de medida que varia de $0-100$. O encontro dos três valores define uma cor [10].

Já o ensaio de rugosidade superficial foi medida com o equipamento Hommel Testes T I000. A rugosidade superficial (Figura 2 ) pode ser definida como um conjunto

Tabela I. Formulações realizadas para o desenvolvimento do trabalho

\begin{tabular}{cccccc}
\hline \multirow{2}{*}{ Vidrados } & \multicolumn{5}{c}{$\%$ corante } \\
\cline { 2 - 6 } & STD (\%) & I (\%) & $\mathbf{3 ( \% )}$ & $\mathbf{5 ( \% )}$ & $\mathbf{7 ( \% )}$ \\
\hline Mate & 100 & 99 & 97 & 95 & 93 \\
Opaco & 100 & 99 & 97 & 95 & 93 \\
Transparente & 100 & 99 & 97 & 95 & 93 \\
\hline
\end{tabular}




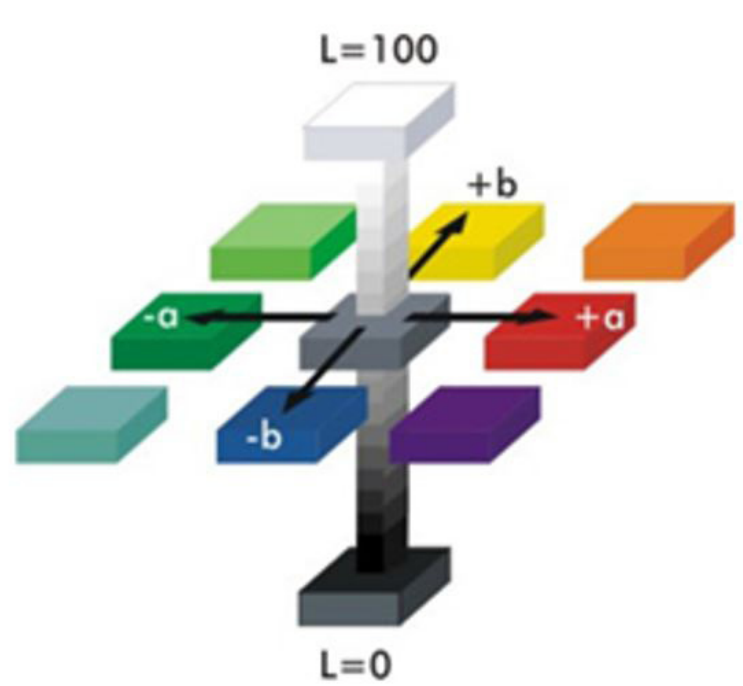

Figura I. Representação do sólido colorido no espaço colorimétrico L*a* b* [10].

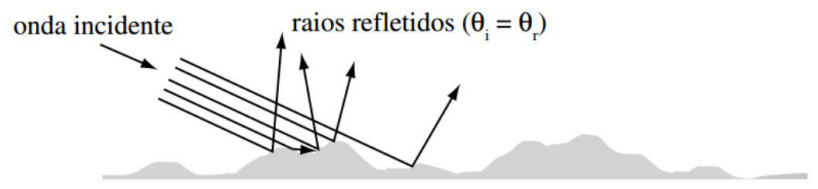

Figura 2. Efeitos da rugosidade superficial sobre a reflexão de luz [I I].

de irregularidades, fundamentalmente com saliências e reentrâncias, que caracteriza uma determinada superfície. No caso das louças cerâmicas a rugosidade superficial influencia diretamente as seguintes propriedades: óticas, durabilidade química, facilidade de limpeza e reflexão da luz incidente [12]. Este procedimento foi aplicado em 5 pontos diferentes de cada corpo de prova, para obtenção de uma média ponderada e melhor resultado.

\section{RESULTADOS E DISCUSSÃO}

A Tabela 2 apresenta o resultado do ensaio de densidade de aplicação dos diferentes tipos de vidrados, juntamente com a percentagem de sólidos (Tabela 3), é possível observar que todos se encontram em uma faixa de aplicação conforme procedimentos internos da empresa fornecedora dos materiais para o tipo gres porcelanato (Densidade dos esmaltes I, $72 \mathrm{~g} / \mathrm{cm}^{3}$ a I,78g/ $/ \mathrm{cm}^{3}$, \% sólidos Mate ( 30 a $35 \%$ ), Opaco (35 a 40\%) e Transparente (40 a 45\%).

As fases cristalinas presentes nas amostras dos vidrados puros e do corante verde estão apresentadas nas Figuras 3 e 4 . As fases cristalinas majoritárias dos vidrados sem adição de corante apresentaram quartzo- $\alpha\left(\mathrm{SiO}_{2}\right.$, cartão $n^{\circ}$ 5-490), albita ( $\mathrm{NaAlSi}_{3} \mathrm{O}_{8}$, cartão $n^{\circ}$ 9-0466), caulinita $\left(\mathrm{Al}_{2} \mathrm{Si}_{2} \mathrm{O}_{5}(\mathrm{OH})_{4}\right.$, cartão I4-008I) e calcita $\left(\mathrm{CaCO}_{3}\right.$, cartão $n^{\circ} 72-1652$ ), porém em proporção e intensidades diferentes.

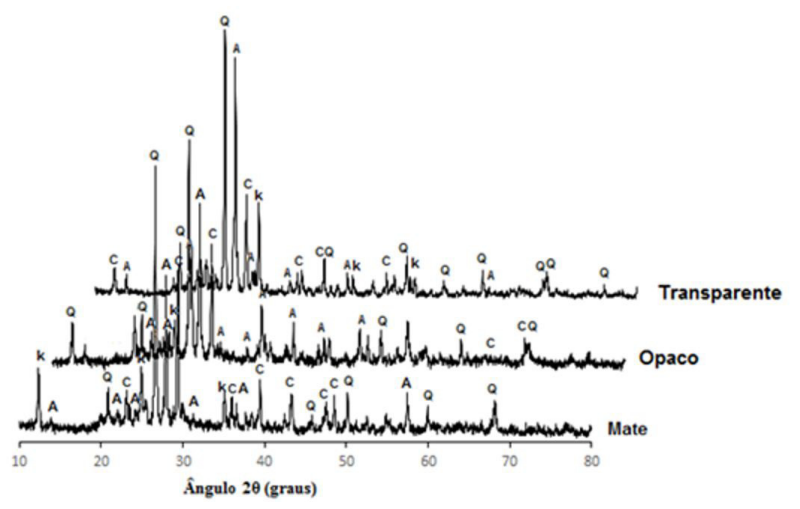

Figura 3. Análise de difração de raios $X$ dos vidrados sem adição de corantes. K - Caulinita; A - Albite; Q - Quartzo; C - Calcita.

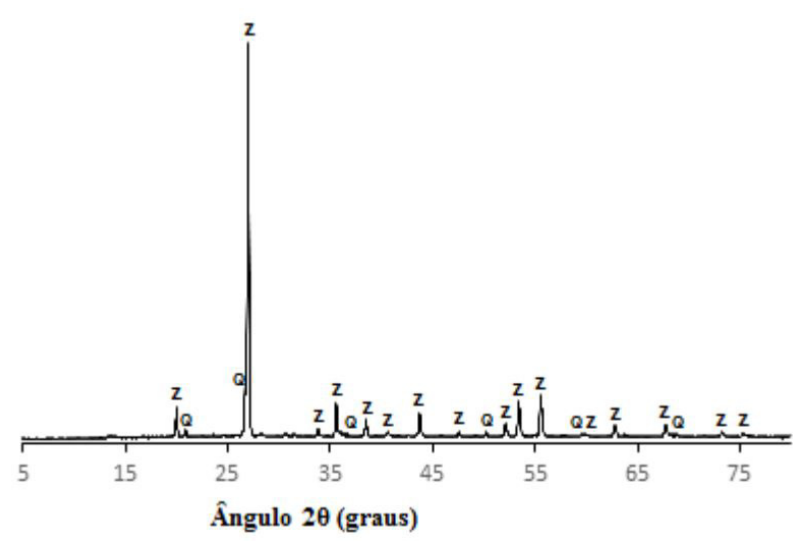

Figura 4. Análise de difração de raios $X$ do corante verde. Z - Zircão; Q - Quartzo.

Tabela 2. Densidades utilizadas para a aplicação dos vidrados

\begin{tabular}{cc}
\hline \multicolumn{2}{c}{ Densidade de aplicação } \\
\hline Vidrado opaco & $\mathrm{I}, 76 \mathrm{~g} / \mathrm{cm}^{3}$ \\
Vidrado mate & $\mathrm{I}, 75 \mathrm{~g} / \mathrm{cm}^{3}$ \\
Vidrado transparente & $\mathrm{I}, 73 \mathrm{~g} / \mathrm{cm}^{3}$ \\
\hline
\end{tabular}

Tabela 3. Percentuais de sólidos dos vidrados

\begin{tabular}{cc}
\hline Vidrados & (\%) Sólidos \\
\hline Mate & 34 \\
Opaco & 36 \\
Transparente & 40 \\
\hline
\end{tabular}

Além disso, percebe-se certa quantidade de fase amorfa nestes vidrados, devido, provavelmente, à frita tipicamente existente em suas composições.

Já a amostra do corante verde, apresentou as fases de quartzo- $\alpha\left(\mathrm{SiO}_{2}\right.$, cartão $\left.\mathrm{n}^{\circ} 5-490\right)$ e zircão (silicato de zircônio $\left(\mathrm{ZrSiO}_{4}\right.$, cartão n ${ }^{\circ}$ 6-266). A fase zircão representa para os vidrados um veículo transportador do pigmento verde, que significa ser um pigmento encapsulado ou de oclusão. Neste caso, o que ocorre é que o cromóforo está 
encapsulado dentro da matriz cristalina cerâmica de silicato de zircônio (como rede hospedeira) que é altamente estável, protegendo-o de agressões dos componentes do vidrado e estabilizando-o para desenvolver melhor a cor verde no vidrado [13].

O pigmento verde é obtido na matriz zircônia com os íons cromóforos do cromo [14]. Este mecanismo é uma linha de pesquisa que tem despertado grande interesse nos últimos anos, por facilitar o transporte da cor e melhorar a estabilidade da cor desejada.

A coloração desenvolvida depende da quantidade do pigmento cromóforo retido na rede cristalina e do grau de inclusão da via empregada, para facilitar o desenvolvimento da cor desejada [13,14]. A matriz zircônia é altamente utilizada por suas ótimas características, físico-químicas, tais como: baixa reatividade química, alto índice de refração, atuação como cristal hospedeiro, elevada rigidez, dureza e resistência mecânica [15].

As dilatometrias dos vidrados cerâmicos encontradas são apresentadas na Tabela 4.

Medidas no intervalo de temperatura compreendido entre 25 a $1000^{\circ} \mathrm{C}$.

A temperatura que correspondente à dilatação máxima denomina-se ponto de amolecimento ( $\mathrm{Ta}$ ). A faixa Ta das amostras sem corante não se nota com clareza para o vidrado mate e transparente, está por meio de $800^{\circ} \mathrm{C}$ e para o vidrado opaco aproximadamente $750^{\circ} \mathrm{C}$. Os coeficientes de dilatação dos vidrados são bastante semelhantes entre si pelo fato de serem constituídos pelos mesmos minerais antes de serem queimados.

As análises dilatométricas dos vidrados com adição de $7 \%$ praticamente não alterou a temperatura de amolecimento, se manteve próximo dos $800^{\circ} \mathrm{C}$. Porém sua dilatação diminuiu isso se deve em função do corante conter fases de Zircão (silicato de Zircônio) que tem dilatometria mais baixa que dos vidrados. $O$ silicato de zircônio têm baixos coeficientes de expansão térmica $\left(40 \times 10^{-7}{ }^{\circ} \mathrm{C}^{-1}\right)$ comparado ao outros silicatos.

Como foi acrescentada uma porcentagem desse material ele diminuiu a dilatometria de todos os vidrados, esse dado se faz importante para os vidrados que utilizam proporções altas de corantes em suas formulas, podendo acarretar em problemas de acoplamento no processo de sinterização. As dilatações dos vidrados com a adição do corante estão na Tabela 5.

A Figura 5a, b, c apresentam os corpos de prova após a sinterização.

Visualmente percebe-se a diferença de tonalidade que o corante desenvolve em cada tipo de vidrado. Observa-se, ainda, que à medida que aumentou a percentagem de corante, houve um desenvolvimento maior em sua cor. No entanto, com as quantidades de 5 e $7 \%$ já fica difícil identificar uma diferença significativa a olho nu, o que indica que é por meio
Tabela 4. Dilatometrias dos vidrados cerâmicos sem adição de corantes

\begin{tabular}{cl}
\hline \multicolumn{2}{c}{ Dilatometria } \\
\hline Vidrado transparente & $\alpha 86,53 \times 10^{-7}{ }^{\circ} \mathrm{C}^{-1}$ \\
Vidrado opaco & $\alpha 76,57 \times 10^{-7}{ }^{\circ} \mathrm{C}^{-1}$ \\
Vidrado mate & $\alpha 68,33 \times 10^{-7} \mathrm{C}^{-1}$ \\
\hline
\end{tabular}

Tabela 5. Dilatometrias dos vidrados cerâmicos com adição de corantes

\begin{tabular}{cc}
\hline \multicolumn{2}{c}{ Dilatometria } \\
\hline Vidrado transparente & $\alpha 82,61 \times 10^{-7}{ }^{\circ} \mathrm{C}^{-1}$ \\
Vidrado opaco & $\alpha 73,09 \times 10^{-7}{ }^{\circ} \mathrm{C}^{-1}$ \\
Vidrado mate & $\alpha 65,31 \times 10^{-7} \mathrm{C}^{-1}$ \\
\hline
\end{tabular}

a)

b)

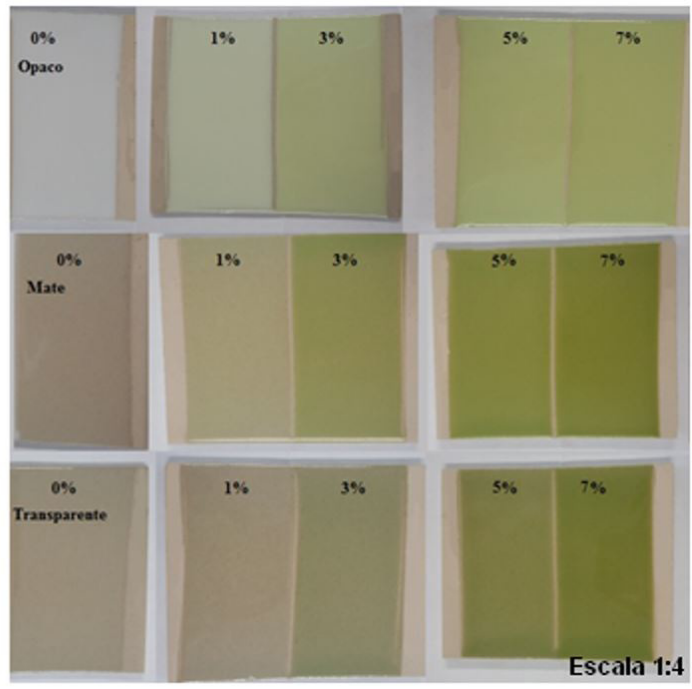

Figura 5. Corpos cerâmicos opacos após a queima. (a) Vidrado Opaco; (b) Vidrado Transparente; (c) Vidrado Mate.

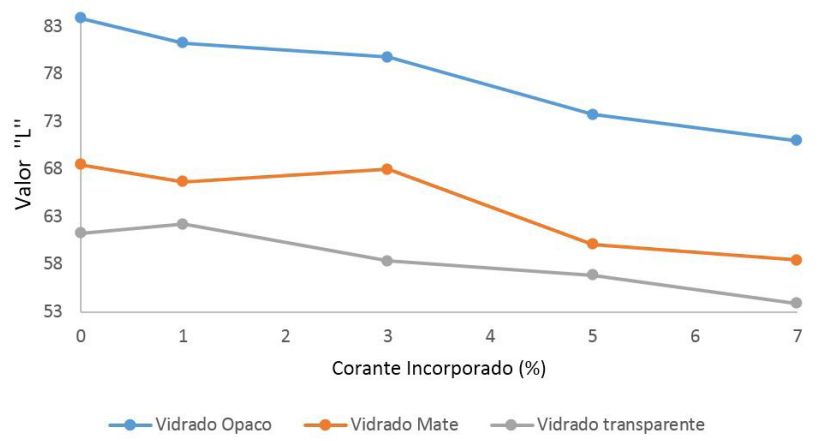

Figura 6. Resultado da análise colorimétrica L**

destes valores que os vidrados atingem a sua estabilidade com este corante e começa a ocorrer saturação.

Numa análise geral dos dados colorimétricos (Figuras 6, 7 e 8), evidenciou-se o predomínio de valores $a^{*}$ negativos, que no sólido de cores localiza-se na região da tonalidade verde. À medida que se adiciona o corante verde a coordenada a* aumenta, desenvolvendo melhor a tonalidade verde, que corresponde ao aspecto dos vidrados 
a olho nu. É possível observar também uma tendência geral na diminuição dos valores de $L^{*}$ devido à diminuição da luminosidade e ao aumento da coordenada $b^{*}$, indicando um deslocamento no sentido da cor amarela.

Nas composições com I a 5\% de corante, a cor verde vai-se desenvolvendo à medida que se adiciona o corante, obtendo-se um a* cada vez mais negativo. Com a adição de $5 \%$ observa-se uma estabilização da cor, já que, com a adição de $7 \%$, ocorre um aumento não significativo no seu desenvolvimento. Numa análise mais específica percebe-se que o vidrado opaco foi o que atingiu os maiores valores de $a^{*}$ negativos desenvolvendo assim a cor verde mais intensamente que nos outros vidrados. Com apenas I\% de adição de corante no vidrado opaco, já se obteve o valor de $-6,258$, enquanto que nos vidrados mate e transparente apenas $-2,336$ e 0,265, respetivamente. Os vidrados mate e opaco apresentaram valores de $L^{*}$ mais baixos, representando também tons mais escuros (com menor claridade).

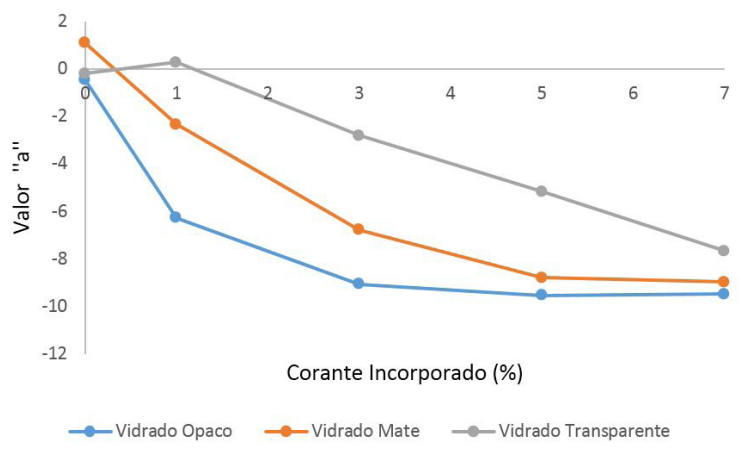

Figura 7. Resultado da análise colorimétrica a*.

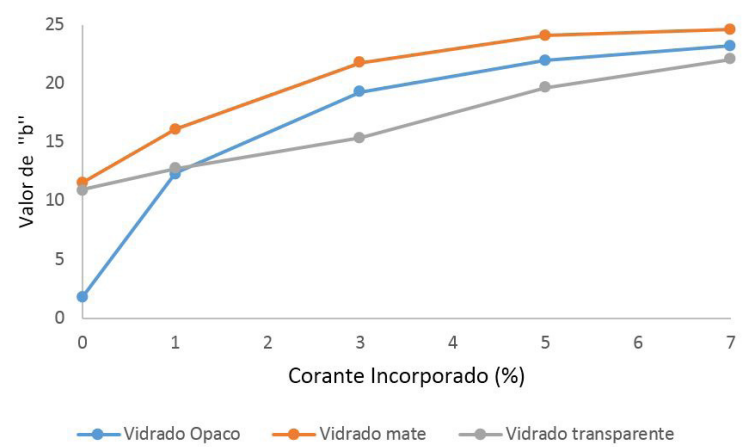

Figura 8. Resultado da análise colorimétrica b*

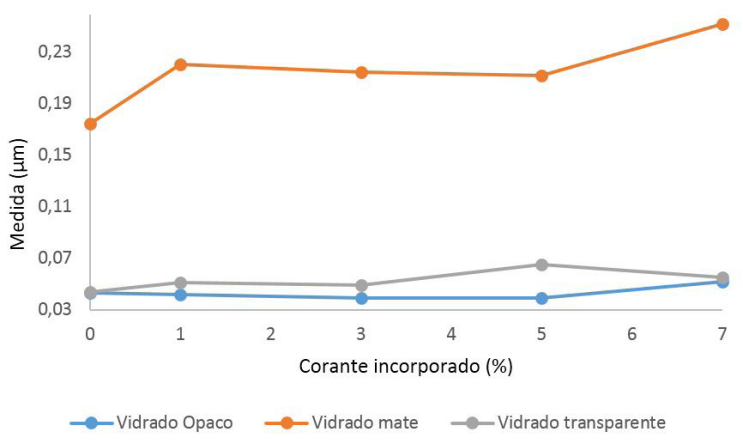

Figura 9. Resultados da análise da rugosidade superficial.
Os resultados da análise superficial apresentam-se na Figura 9, demostrando que o vidrado mate foi o que apresentou maior rugosidade superficial. Um vidrado mate contém, em geral, partículas opacificantes na superfície que quebram a refração espectral [I I]. Estas partículas, porém acabam por não se fundir completamente gerando uma rugosidade superficial mais elevada que nos outros dois casos. Já os vidrados opaco e transparente apresentaram valores semelhantes e menores. Estes vidrados apresentam uma superfície mais lisa e brilhante, por não conter saliências dos grânulos não fundidos, e poros abertos na superfície, devido a completa fusão dos componentes.

\section{CONCLUSÕES}

Juntamente com a evolução tecnológica, a produção de placas cerâmicas de revestimentos teve a necessidade de produzir produtos sem oscilação de cor e com maior qualidade. Atualmente, com estudos técnicos nas áreas dos vidrados e corantes isto é cada vez mais possível, porém ainda a necessidade de melhorias.

Com a análise de raios $X$ foi possível confirmar que o zircão foi o agente cromóforo transportador da cor verde. $O$ silicato de zircônio é conhecido como um agente opacificante, no entanto, quando usado em percentagens até $7 \%$, este age apenas como veículo transportador da cor verde, sem alteração da opacidade.

Para a obtenção de outros resultados, seria necessário realizar ensaios com maior percentagem de corante, de forma a verificar se o silicato de zircônio influencia a opacidade dos vidrados.

Com dados obtidos no trabalho mostram que a incorporação do corante verde nos três vidrados (mate, opaco, transparente) apresenta um bom desenvolvimento da cor.

Com a adição de $7 \%$ o vidrado mate e opaco apresentaram saturação do corante.

A dilatometria dos vidrados coloridos com $7 \%$ de corante verde tive uma diminuição de até 4 pontos. Mesmo não apresentando defeitos após a queima, é necessário ter uma atenção especial, pois pode afetar a qualidade do produto final em um processo de fabricação.

A rugosidade não foi afetada pelo corante. $O$ vidrado mate foi o que apresentou a maior rugosidade superficial, por conter matérias primas com maior granulometria que não se fundem por completo na queima

\section{Agradecimentos}

Os pesquisadores agradecem ao CNPq, à CAPES, as empresas que de alguma forma contribuíram para o desenvolvimento deste trabalho e aos professores da Universidade de Aveiro que auxiliaram no estudo. 


\section{REFERÊNCIAS}

I Renau RG. Pastas y vidriados en la fabricación de pavimentos y revestimientos cerámicos. Ibérica: Castellón: Faenza Editrice; 1994. 25 I p.

2 Gilbertoni C. Estudo da previsibilidade de tonalidades na decoração em vidrados transparentes [dissertação de mestrado]. São Carlos: Universidade de São Carlos; 2008.

3 Eppler RAE, Eppler DR. Glazes and glass coatings. Ohio: The American Ceramic Society; 2000. 332 p.

4 Sichi M. As recentes técnicas colorimétricas e tintométricas na gestão industrial da cor. Aplicações e possíveis desenvolvimentos no campo cerâmico. Revista Cerâmica Informação. 2007;55:33-38.

5 Gomes CF. Argilas: o que são e para que servem. Lisboa: Calouste Gulbenkian Eds.; 1986.

6 Martinho G. Reformulação da composição das pastas de grés - optimização da relação custo/qualidade. (dissertação de mestrado). Aveiro: Universidade de Aveiro; 2008.

7 Lopes PE, Castelló JBC, Cordoncillo EC. Esmaltes y pigmentos cerámicos. Castellón: Faenza Editrice lbérica; 200 I. $300 \mathrm{p}$.

8 Oliveira HE, Labrincha J. Esmaltes e engobes para monoporosa. Cerâmica Industrial. 2002;7(2):25-29.

9 Nachev S, De Rango P, Delhomme B, Planté D, Zawilski B. Longa, F et al. In situ dilatometry measurements of $\mathrm{MgH} 2$ compacted disks. Journal of Alloys and Compounds, 2013:580(Suplemento):SI83-SI86.

10 Silval RA, Petterll CO, Schneiderll IA. Avaliação da perda da coloração artificial de ágatas. Rem: Revista Escola de Minas, 2007:60(3), 477-482.

I Serafim B, Genaari R, Melchiades F, Boschi AO. Rugosidade superficial de revestimentos cerâmicos. Cerâmica Industrial, II;2006:15-18.

12 Carpinetti LC, Gonçalves EV, Porto AJV, Jasinevicius R. Rugosidade superficial: conceitos e princípios de medição. São Carlos: Serviço Gráfico USP-EESC; 1996. 51 p.

13 Possamai DV. Síntese e caracterização do pigmento cerâmico de hematita, obtida a partir de carepa de aço, encapsulada em sílica amorfa obtida a partir de casca de arroz [dissertação de mestrado]. Florianópolis: Universidade ederal de Santa Catarina; 2005.

14 Lambies VE, Rincón JM. Study of the mechanism of formation of a zircon-cadmium sulphoselenide pigment. Transactions of the Bristish Ceramic Society, 80;1981:105-108.

15 Dias CA. Produção de pigmentos inorgânicos a base de $\mathrm{ZrSiO}_{4}$ com incorporação de pasta eletrolítica de pilhas [dissertação de mestrado]. Ponta Grossa: Universidade Estadual de Ponta Grossa; 2009.

Recebido em: 22 Out. 2015

Aceito em: 16 Jan. 2017 